\title{
Competition between sodium oleate and sodium silicate for a silicate/oleate modified magnetite surface studied by in situ ATR-FTIR spectroscopy
}

\author{
Payman Roonasi $^{\mathrm{a}, *}$, Xiaofang Yang ${ }^{\mathrm{a}, \mathrm{b}}$, Allan Holmgren ${ }^{\mathrm{a}}$ \\ ${ }^{a}$ Division of Chemistry, Department of Chemical Engineering and Geosciences, Luleå University of Technology, SE-97187 Luleå, Sweden \\ ${ }^{\mathrm{b}}$ Research Center for Eco-Environmental Sciences, Chinese Academy of Sciences, Beijing 100085, China
}

\section{A R T I C L E I N F O}

\section{Article history:}

Received 30 August 2009

Accepted 2 December 2009

Available online 6 December 2009

\section{Keywords:}

ATR-FTIR spectroscopy

Magnetite

Oleate

Silicate

Depressive effect

Adsorption kinetics

\begin{abstract}
A B S T R A C T
Attenuated Total Reflection (ATR) IR spectroscopy was utilized to monitor adsorption of sodium oleate and sodium silicate onto synthetic magnetite at $\mathrm{pH}=8.5$, both individually and in a competitive manner. Oleate was adsorbed within a concentration range of $0.01-0.5 \mathrm{mM}$. It was observed that adsorption of oleate increased linearly with increasing concentration of oleate in solution up to a concentration of $0.1 \mathrm{mM}$. The infrared spectrum of oleate showed a broad single band at $1535 \mathrm{~cm}^{-1}$ assigned to the asymmetric stretching vibration of carboxylate, implying chemisorption of oleate to the magnetite surface. The kinetics of oleate adsorption followed a pseudo first-order reaction with an apparent rate constant of $k_{1}=0.030 \pm 0.002 \mathrm{~min}^{-1}$. Competitve adsorption of silicate and oleate was performed either by adding silicate solution to a magnetite film initially equilibrated with $0.1 \mathrm{mM}$ oleate or adding oleate solution to magnetite treated with silicate solutions in the concentration range $0.1-5 \mathrm{mM}$. It was shown that silicate, within reasonable time, had only minor effect on the amount of oleate already adsorbed on magnetite. On the other hand, oleate did not efficiently compete with silicate if the latter substance was already adsorbed on the iron oxide.
\end{abstract}

(c) 2009 Elsevier Inc. All rights reserved.

\section{Introduction}

The agglomeration of finely ground iron ore concentrates into magnetite pellets is a complex surface chemical process involving a mixture of various components such as magnetite, bentonite, water-glass, olivine, as well as ions dissolved in the process water. In addition it may be necessary to use a collector for reversed flotation of apatite from magnetite, as is the case at Luossavaara-Kirunavaara $A B(L K A B)$ in Sweden. This reagent is applied to minimize the apatite content by froth flotation, but a small amount of the collector may also adsorb at the magnetite particle surfaces and such a wetting modification was recently shown to affect the strength of the green pellets formed in the pelletizing process [1]. Thus, it is important to reduce the adsorption of this collector in order to further improve the strength of the pellets. Although the chemical structure of the collector is unspecified by the manufacturer, from NMR and IR spectra of this compound it was clear that the collector contains a number of carbonyl groups, double bond(s), methyl $\left(\mathrm{CH}_{3}\right)$ and methylene $\left(\mathrm{CH}_{2}\right)$ entities. In this study we have used sodium oleate as a model collector molecule. Oleate, which is a well known surfactant and collector, consists of a carboxylate head group, a hydrocarbon chain, and a double bond at

\footnotetext{
* Corresponding author. Fax: +46920491399.

E-mail address: Payman.roonasi@ltu.se (P. Roonasi).
}

the C:9 position of the $C 18$ alkyl chain. Attenuated Total Reflection (ATR) infrared spectroscopy was utilized, a technique that has been widely applied to study surface adsorption from aqueous solution onto finely dispersed solids including metal oxides e.g. [2-8]. ATR spectroscopy has also been used to study surface reactions related to flotation [9-15]. Especially the in situ method is advantageous since it admits the adsorbed species to be monitored while the mineral is in contact with the solution. This advantage not only allows one to acquire information regarding the nature of the species, but also the rate of adsorption can be studied in situ i.e. in real time $[3,8-10]$.

The aim of the present study was primarily to investigate the adsorption properties of oleate on the magnetite particle surfaces including the adsorption kinetics and the competition between oleate and sodium silicate for the magnetite surface. Silicate species adsorbed at magnetite will make the iron oxide surface hydrophilic, which is advantageous for the particle agglomeration process, whilst adsorbed collector would have the opposite effect. Sodium silicate (known as water-glass) is one of the mostly used modifying reagents in flotation. It is well known that the speciation of silicate species in aqueous solution depends on $\mathrm{SiO}_{2}: \mathrm{Na}_{2} \mathrm{O}$ ratio, $\mathrm{SiO}_{2}$ concentration, $\mathrm{pH}$, temperature, and aging [16-20]. These parameters therefore play a significant role in its application in surface modification processes. Here $\mathrm{pH}$ was adjusted to intermediate value (8.5), close to the $\mathrm{pH}$ of the process water at LKAB. Poly- 
merization of silicate is known to be more extensive at intermediate $\mathrm{pH}$ values than at higher $\mathrm{pH}[20]$.

\section{Materials and methods}

\subsection{Materials and reagents}

Magnetite was synthesized as previously described [3,20,21]. The small magnetite particles implied a high surface area $\left(97.7 \mathrm{~m}^{2} / \mathrm{g}\right)$, which is advantageous for spectroscopic measurements and these particles were used as a model system for magnetite from the iron ore.

Sodium oleate ( $99 \%$ ) was obtained from Sigma. Fresh solutions of oleate were prepared by dissolving sodium oleate in water. Water-glass reagent with a modulus $\left(\mathrm{SiO}_{2} / \mathrm{Na}_{2} \mathrm{O}\right.$ ratio $)$ of 3.3 was used as the silicate solution source. The water-glass solutions were diluted to a desirable concentration just before the experiment. Analytical grade of $\mathrm{NaOH}$ and $\mathrm{HCl}$ were used for $\mathrm{pH}$ adjustment. Milli-Q water (Millipore Corp.) was used in all stages for preparation of sodium oleate and water-glass solutions and adsorption measurements.

\subsection{ATR-FTIR measurements}

\subsubsection{Instrumentation and experimental set up}

The internal reflection element (IRE) was thoroughly rinsed with ethanol and Milli-Q water before deposition of a magnetite layer. The magnetite particles were deposited over the ZnS-IRE ( $50 \mathrm{~mm} \times 20 \mathrm{~mm} \times 2 \mathrm{~mm}$ ) by evenly spreading a few drops of an as-synthesized magnetite suspension over the crystal and drying it in a vacuum desiccator. A single sided rectangularly shaped flow through cell, made of stainless steel, was used. The cell was connected to a $250 \mathrm{ml}$ reservoir containing $150 \mathrm{ml}$ solution via Viton tubings and the solutions were circulated through the cell at a rate of $5 \mathrm{ml} / \mathrm{min}$ (for further details, see Ref. [3]). All experiments were performed at room temperature and the reservoir was protected from air by a flow of argon. The $\mathrm{pH}$ value was probed during the experiment using a glass electrode. The IR spectra were recorded on a Bruker IFS 66v/S equipped with a DTGS detector and typically 350 co-added scans were recorded at a resolution of $4 \mathrm{~cm}^{-1}$. Data acquisition as well as data processing and analysis were carried out by means of the OPUS software.

\subsubsection{Adsorption measurements}

2.2.2.1. Oleate adsorption. Milli-Q water at $\mathrm{pH}=8.5$ was continuously circulated through the cell for 30 min before the background spectrum was collected. Afterwards, a known volume of the freshly prepared sodium oleate solution was added to the reaction vessel to acquire the desired spectra. The sample spectra were recorded using the repeated measurements facility until no significant increase in intensity of the $\mathrm{C}-\mathrm{H}$ stretching frequency was observed. This was assumed to represent the adsorption maximum at the given concentration. The same procedure was repeated for oleate concentrations between $0.01 \mathrm{mM}$ and $0.5 \mathrm{mM}$. Although the reported critical micellization concentration (CMC) of aqueous sodium oleate solutions varies a lot in the literature (0.7-4.8 mM), [22,23] the concentration range used should be below the CMC value.

A new magnetite film was deposited on the IRE for each kinetic experiment and after the background spectrum had been recorded. The background solution (Milli-Q water at $\mathrm{pH}=8.5$ ) was then replaced by oleate solution (further details can be found in Ref. [3]).

Experiments were also performed using aqueous oleate solutions in the concentration range $0.05-0.5 \mathrm{mM}$ and a bare $\mathrm{ZnS}$ crystal (without deposited magnetite) to make sure the observed intensity was not due to oleate adsorbed onto the bare ZnS-IRE or from oleate in aqueous solution. Only negligible IR absorption, due to oleate, was detected in these experiments.

2.2.2.2. Adsorption of water-glass on oleate modified magnetite. The effect of water-glass on oleate adsorption at the magnetite surface was performed as follows:

An aqueous solution of $0.1 \mathrm{mM}$ oleate was equilibrated with the magnetite surface and spectra were recorded until adsorption equilibrium ( $\mathrm{ca} .80 \mathrm{~min}$ ), in the same way as described in Section 2.2.2.1. Then, a given amount of water-glass was added to obtain a silicate concentration of $0.01 \mathrm{mM}$ and subsequently spectra of adsorbed silicate were monitored with time. The experiment was continued by increasing the concentration of silicate to $0.06 \mathrm{mM}, 0.2 \mathrm{mM}, 1 \mathrm{mM}$, and $5 \mathrm{mM}$. Spectra were recorded 75 min after each addition. The $\mathrm{pH}$ of the aqueous solutions (Milli-Q water) was 8.5.

2.2.2.3. Adsorption of oleate on silicate modified magnetite. A $0.1 \mathrm{mM}$ aqueous silicate solution was prepared $(\mathrm{pH}=8.5)$. This silicate solution was circulated for $100 \mathrm{~min}$ in contact with the magnetite surface while the spectra were collected in the same way as described under Section 2.2.2.1. Subsequently, sodium oleate was added to this solution to obtain a $0.1 \mathrm{mM}$ solution with respect to oleate. This procedure was repeated with initial silicate concentrations of $0.4 \mathrm{mM}, 1 \mathrm{mM}$, and $5 \mathrm{mM}$ before adding sodium oleate $(0.1 \mathrm{mM})$. The latter sequence of silicate/oleate addition is natural since silicate work both as a depressor and as a dispersing agent.

\section{Results and discussion}

\subsection{Adsorption of oleate onto magnetite}

Fig. 1 shows IR spectra of oleate adsorbed on magnetite at different concentrations and Fig. 2 depicts the plot of integrated absorbance in $\mathrm{C}-\mathrm{H}$ stretching region $\left(2800-3000 \mathrm{~cm}^{-1}\right)$ versus equilibrium oleate concentration in solution. As evident from Figs. 1 and 2, the adsorption increased nearly proportional to oleate

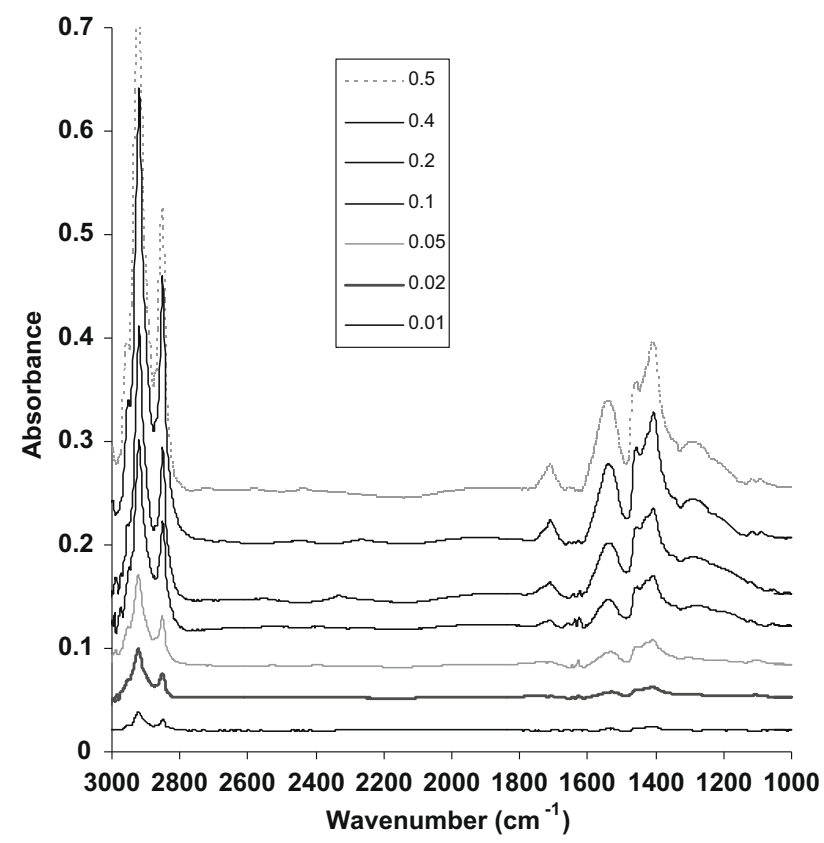

Fig. 1. Infrared spectra of oleate adsorbed on magnetite from 0.01-0.5 mM aqueous oleate solutions. The insert shows the bulk oleate concentration in $\mathrm{mM}$ and spectra were shifted along the absorbance axis for clarity. 


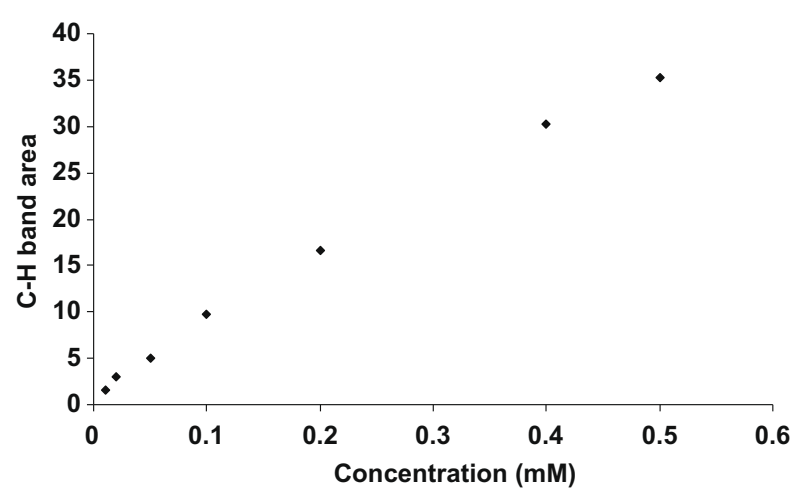

Fig. 2. A plot of the integrated absorbance in the $\mathrm{C}-\mathrm{H}$ stretching region (2800$3000 \mathrm{~cm}^{-1}$ ) versus equilibrium oleate concentration in solution showing a nearly linear correlation with adsorbed oleate.

concentration in solution at low concentrations but the slope of the curve decreased at higher concentration although not reaching an equilibrium plateau value within the concentration range studied. No kink was observed in the absorbance versus concentration isotherm (Fig. 2). However, this does not exclude the formation of a second layer of physisorbed oleate simultaneously as the monolayer is formed.

It should be noticed that the observed intensity is due to oleate adsorbed on magnetite since the adsorption onto the $\mathrm{ZnS}$ crystal is negligible (Section 2.2.2.1) and so is absorption due to oleate in solution. A similar trend in oleate adsorption onto hematite was observed by Ofor [24], who studied oleate concentrations up to $1.07 \mathrm{mM}$. Likewise, Shibata and Fuerstenau [25] found increased oleate adsorption with increasing concentration up to $10^{-4} \mathrm{M}$.

The band assignments of oleate and oleic acid are well established in the literature [26]. There are four main regions in the IR spectrum of oleate which are commonly considered to determine and characterize the nature of adsorbed oleate at mineral surfaces:

Region I comprises $\mathrm{C}-\mathrm{H}$ stretching including symmetric and asymmetric stretching of $\mathrm{CH}_{2}$ and $\mathrm{CH}_{3}$ entities between $2800 \mathrm{~cm}^{-1}$ and $3000 \mathrm{~cm}^{-1}$ and the vinylic $=\mathrm{C}-\mathrm{H}$ band above $3000 \mathrm{~cm}^{-1}$. The bands in this region (either the integrated absorbance over the whole $\mathrm{CH}$ range or only the $\mathrm{CH}_{2}$ asymmetric stretching intensity) are frequently used for quantitative measurements of adsorbed organic substances [11,27-29]. The frequency position of the asymmetric $\mathrm{CH}_{2}$ stretch has also been used as indicator of the conformation of the alkyl chains e.g., [30-33].

Regions II, III and IV comprise the carboxylic function, where the carbonyl vibration appears around $1710 \mathrm{~cm}^{-1}$ (II), the carboxylate asymmetric (III), and the symmetric (IV) stretching frequencies are located at about $1550 \mathrm{~cm}^{-1}$ and $1420 \mathrm{~cm}^{-1}$, respectively. Within the latter region (region IV) also bands due to the symmetric and asymmetric bending of methylene and methyl groups appear. The frequency distance between the two carboxylate vibrations has been proposed as an aid to distinguish between the structure of the surface complexes formed between organic acids and metal oxides [34,35].

The $\mathrm{CH}_{2}$ and $\mathrm{CH}_{3}$ stretching bands are the most intense (Fig. 1) at all concentrations studied. A closer look at the frequency position of the asymmetric and symmetric $\mathrm{CH}_{2}$ stretching bands at different concentrations demonstrates a shift toward lower frequency with increasing concentration up to $0.1 \mathrm{mM}\left(\sim 2 \mathrm{~cm}^{-1}\right)$ but becomes nearly constant at higher concentrations (Fig. 3). This behavior indicates a decrease in the number of gauche conformers up to $0.1 \mathrm{mM}$, where after the alkyl chain packing becomes almost constant. The transfer of the alkyl chain from an aqueous environment at low concentration to a hydrocarbon environment at the mineral surface could be responsible for the frequency shift. Both

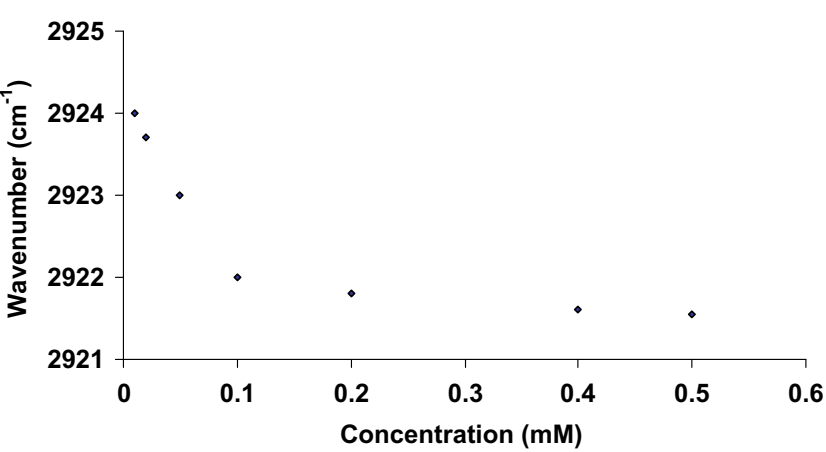

Fig. 3. The methylene stretching region of oleate adsorbed on magnetite illustrating the shift in the position of the $\mathrm{CH}_{2}$ asymmetric stretching band towards lower frequency with increasing oleate concentration.

an increased packing of the alkyl chains during monolayer formation and the formation of a second physisorbed layer of oleate molecules are therefore in accordance with this change in frequency.

The single broad feature at $1535 \mathrm{~cm}^{-1}$ (Fig. 1) was assigned to the asymmetric carboxylate stretching vibration, whilst the weak band at $1711 \mathrm{~cm}^{-1}$ is assigned to the carbonyl vibration of oleic acid. The latter band became more prominent in the spectra at higher $(\geqslant 0.2 \mathrm{mM})$ oleate concentration, indicating formation of carboxylic groups. An asymmetric carboxylate stretching at about $1535 \mathrm{~cm}^{-1}$ has been used as a proof of chemisorbed oleate on calcium minerals [36]. The configuration of carboxylate bonded to magnetite is determined using the frequency difference between symmetric and asymmetric $\mathrm{COO}^{-}$stretching vibrations $(\Delta \mathrm{v})$ [34,35,37]. The observed $\Delta v=110 \mathrm{~cm}^{-1}$ in this work (1425$1535 \mathrm{~cm}^{-1}$ ) is less than $135 \mathrm{~cm}^{-1}$ obtained for non-adsorbed oleate in accordance with a bidentate mononuclear configuration. In our previous work on oleate adsorbed on magnetite using DRIFT spectroscopy [21], it was concluded that the configuration of adsorbed oleate at the magnetite surface is predominantly a chelate with a small contribution from bidentate bridging, which is in accordance with the present result.

The fact that significant adsorption occurred at alkaline $\mathrm{pH}$ ( $\mathrm{pH}=8.5$ in this case) which is higher than the PZC of magnetite ( $\sim 6.5$ ) clearly indicates chemisorption, although PZC varies somewhat in the literature with $\mathrm{p} K_{\mathrm{a} 1} \sim 5$ and $\mathrm{p} K_{\mathrm{a} 2} \sim 8$ [38]. The majority of sodium oleate in solution is in the form of $\mathrm{Ol}^{-}$at the $\mathrm{pH}$ and concentrations used here although other species such as $\mathrm{Ol}_{2}^{2-}, \mathrm{HOl}_{2}^{-}$ and $\mathrm{HOl}$ may also coexist but in non-detectable concentration. The magnetite surface is negatively charged at this $\mathrm{pH}$ implying that the surface sites represent a distribution of $\left(\equiv \mathrm{FeO}^{-}\right)$and neutral entities $(\equiv \mathrm{FeOH})$. Oleate is therefore assumed to replace surface hydroxyl groups. The reaction might be expressed as follows:

$[\equiv \mathrm{Fe}(\mathrm{II}, \mathrm{III})-\mathrm{OH}]+\mathrm{Ol}^{-} \Longleftrightarrow[\equiv \mathrm{Fe}(\mathrm{II}, \mathrm{III})-\mathrm{Ol}]+\mathrm{OH}^{-}(\mathrm{Ol}=$ oleate $)$,

Thus, the charge of the magnetite surface at $\mathrm{pH} 8.5$ and the infrared band assignments both indicate that oleate forms a chemisorbed layer at the magnetite surface with possible contribution from physisorbed oleate. Physisorption should be more probable at oleate concentrations approaching the CMC value.

\subsubsection{Kinetics of oleate adsorption onto magnetite}

The kinetics was studied by in situ monitoring the adsorption of oleate onto the magnetite surface with time. The integrated absorbance over the $\mathrm{C}-\mathrm{H}$ stretching range was assumed to be proportional to the amount of oleate adsorbed. Fig. 4 shows the increase in adsorption with time. Assuming pseudo-first-order kinetics, the following equation can be derived: 


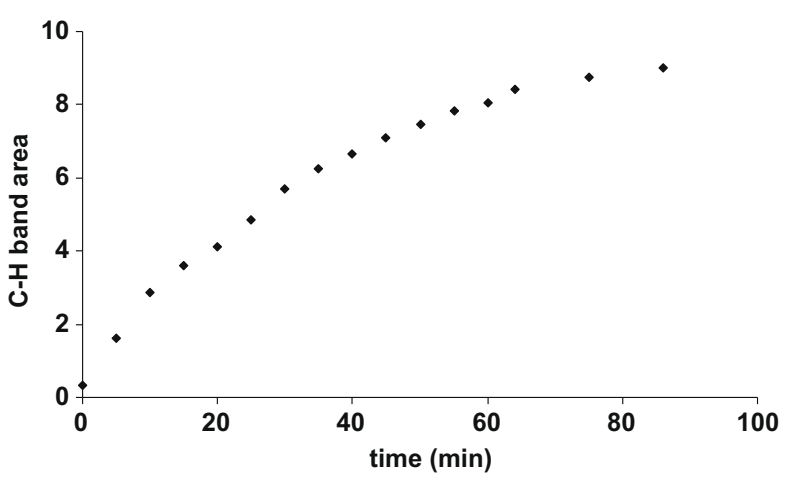

Fig. 4. Kinetics of oleate adsorption on magnetite shown as a plot of integrated absorbance in the $2800-3000 \mathrm{~cm}^{-1}$ region versus time. The bulk concentration of oleate was $0.1 \mathrm{mM}$.

$\ln \left[A_{m} /\left(A_{m}-A_{t}\right)\right]=k_{1} \cdot t$

where $k_{1}=k_{2} \cdot C_{\mathrm{b}}$, is the pseudo-first order rate constant, and $C_{\mathrm{b}}$ is the concentration of oleate in the bulk, $t$ is time, $A_{m}$ and $A_{t}$ are absorbances at equilibrium and at time $t$, respectively [9,39].

According to Eq. (2), a plot of $\ln \left[A_{m} /\left(A_{m}-A_{t}\right)\right]$ versus time might confirm first-order behavior and from the gradient of the straight line, $k_{1}$ can be determined. As shown in Fig. 5 , the reaction was confirmed to be first-order with $R^{2}=0.9961$, which demonstrates a good correlation with first-order kinetics. An apparent rate constant of $k_{1}=0.030 \pm 0.002 \mathrm{~min}^{-1}$ was obtained, which was constant within experimental error for all concentrations studied $(0.01 \mathrm{mM}$, $0.02 \mathrm{mM}, 0.05 \mathrm{mM}$, and $0.1 \mathrm{mM}$ ).

It has been shown that adsorption of a number of collectors on mineral surfaces follows (pseudo)first-order kinetics with respect to availability of surface sites. Drelich et al. [13] modeled the adsorption of 10-undecenoic acid and 10-undecyonic acid on fluorite as pseudo-first-order kinetics. Free and Miller [14] used this kinetic model to fit their data on oleate adsorption onto fluorite. Fredriksson et al. [11] showed that the adsorption of heptyl xanthate on a layer of zinc sulfide also followed pseudo-first-order behavior. A similar model was used by Chiem et al. [10] for adsorption of polyacrylamide on a talc surface. Ofor studied adsorption of oleate on hematite and reported that the reaction was first order with respect to oleate concentration in bulk solution and considering the high activation energy, the chemical process was the rate determining step [40].

The good correlation between experimental data for different concentrations and pseudo-first-order kinetics presented here indicates that the adsorption process at the surface controls the

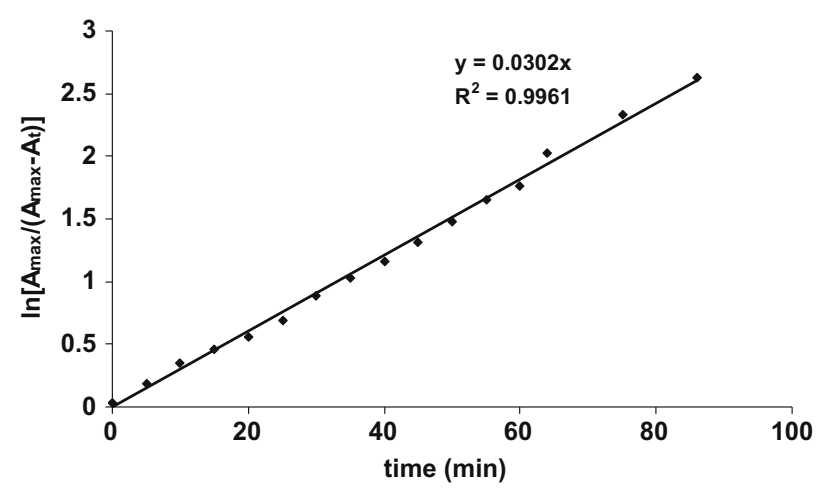

Fig. 5. A plot of $\ln \left(A_{\max } /\left(A_{\max }-A_{t}\right)\right)$ versus time showing that the rate of adsorption of oleate onto magnetite followed a pseudo-first-order reaction. The straight-line is a linear least square fit of the experimental points. rate of adsorption. In this process the oleate molecules replace surface hydroxyl groups and also associated water molecules, so hydrogen bonding interaction should play an important role in the initial step. However, van der Waals interactions between hydrocarbon chains may also affect the reaction rate since already adsorbed oleate molecules should facilitate the adsorption of the next molecule close to the first one thereby possibly building islands of oleate at the surface, islands that grows with time and eventually forms a monolayer. The rate of collector adsorption is of course important in selective flotation. Since the separation of apatite from magnetite seems to work well in practice, the rate of collector adsorption onto apatite should be much larger. However, in the real process it might be more efficient to add the collector step by step since this would reduce high local concentrations of the collector in the flotation pulp. A high local concentration might imply that more of the collector is first adsorbed on magnetite and redistribution of the collector from magnetite surfaces to apatite is probably a comparatively slow process. This will be the subject of further investigations.

\subsection{Adsorption of silicate onto magnetite}

Fig. 6 shows spectra from the adsorption of sodium silicate onto magnetite from $0.1 \mathrm{mM}, 0.4 \mathrm{mM}, 1 \mathrm{mM}$, and $5 \mathrm{mM}$ silicate solutions at $\mathrm{pH}=8.5$. As evident from these infrared spectra, the absorption bands typical for adsorbed silicate species shift to higher frequency with increasing concentration of silicate in solution. This shift caused by higher concentration was recently ascribed to the formation of condensation products between silicate species at the mineral surface [20]. In this context it may be noticed that the adsorption of silicate did not reach an equilibrium plateau value during the time used for equilibration with magnetite (100 min). Silicate was shown to be chemisorbed at magnetite since adsorption was evident at high $\mathrm{pH}$ values $(\mathrm{pH}=10.8)$ where both the adsorbent and the adsorbate are negatively charged $[20,41]$. The rate of adsorption varies with $\mathrm{pH}$ and concentration as shown in Ref. [41].

The $\mathrm{pH}$ and concentration of silicate in addition to $\mathrm{SiO}_{2} / \mathrm{Na}_{2} \mathrm{O}$ ratio (modulus of sodium silicate), temperature, and aging are the main factors determining the properties of silicate species in solution. The distribution diagram of silicate anions in solution as a function of concentration and $\mathrm{pH}$ is available $[20,42,43]$. According to equilibrium calculations at various $\mathrm{pH}$, the monomers $\mathrm{SiO}_{2}(\mathrm{OH})_{2}^{2-}, \mathrm{SiO}(\mathrm{OH})_{3}^{-}$, and $\mathrm{Si}(\mathrm{OH})_{4}$ are dominant at concentrations below $2 \mathrm{mM}$. At $\mathrm{pH}<9$, the monomer $\mathrm{Si}(\mathrm{OH})_{4}$ is the major specie in solution. At concentrations higher than $2 \mathrm{mM}$ and moderate $\mathrm{pH}$ $(7<\mathrm{pH}<9)$, however, amorphous silica will start to precipitate.

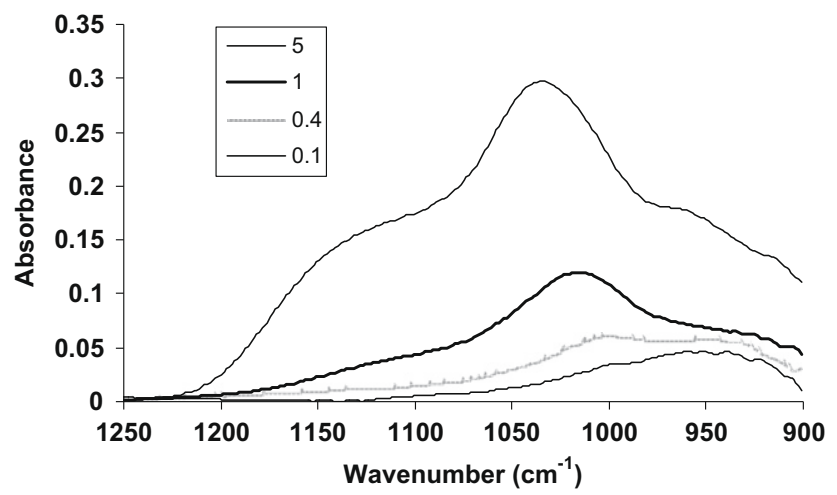

Fig. 6. Infrared spectra of silicate adsorbed on magnetite from aqueous solution. The insert shows the bulk silicate concentrations in mM. Spectra were recorded after equilibration for $100 \mathrm{~min}$. 
In previous contributions we studied the silicate adsorption on magnetite at different $\mathrm{pH}$ and concentrations [20,41]. It turned out that the highest and strongest adsorption took place at moderate $\mathrm{pH}$ and high silicate concentrations where more oligomerized/ polymerized silicates form at the surface. According to the literature $[20,41,44]$, the formation of such species has a stronger affinity for the iron oxide surface due to contribution from many Fe-OSi segments to the strength of adsorption.

Upon adsorption of silicate onto magnetite from a $0.1 \mathrm{mM}$ solution, a prominent IR band appeared at $\sim 950 \mathrm{~cm}^{-1}$. This band was assigned to $\mathrm{FeO}-\mathrm{Si}$ stretching in inner-sphere bidentate monomeric surface complexes, $(\equiv \mathrm{FeO})_{2}-\mathrm{Si}(\mathrm{OH})_{2}$ or $(\equiv \mathrm{FeO})_{2}-\mathrm{Si}(\mathrm{OH}) \mathrm{O}^{-}$ [20]. Increasing the silicate concentration in aqueous solution from $0.4 \mathrm{mM}$ to $5 \mathrm{mM}$ implied that this band was shifted to higher wave numbers. At $0.4 \mathrm{mM}$, a new band appeared above $1000 \mathrm{~cm}^{-1}$, a band that grew in intensity with time. At $1 \mathrm{mM}$ the strongest band was located at $\sim 1020 \mathrm{~cm}^{-1}$ with two distinct shoulders at $\sim 955 \mathrm{~cm}^{-1}$ and $\sim 1120 \mathrm{~cm}^{-1}$. The band at $\sim 955 \mathrm{~cm}^{-1}$ was attributed to bidentate monomeric surface species, whilst the bands at higher frequency viz. $1020 \mathrm{~cm}^{-1}$ and $1120 \mathrm{~cm}^{-1}$ were assigned to oligomeric and/or polymeric surface species. At $5 \mathrm{mM}$, the latter band was strongly enhanced and shifted to still higher frequency. The latter infrared absorption was suggested to be related to a three dimensional silica framework such as amorphous silica particles.

Fig. 7 shows the development of the spectral feature upon adsorbing silicate onto magnetite from $0.4 \mathrm{mM}$ silicate solution. The growth in intensity of the band above $\sim 1000 \mathrm{~cm}^{-1}$ is clear and eventually this band became the strongest one in this spectral region. A similar trend occurred at higher concentration viz., $1 \mathrm{mM}$ and $5 \mathrm{mM}$, and was described as oligomerization or polymerization of silicate at the surface with time [41].

\subsection{Competitive adsorption between oleate and silicate for magnetite}

In the reversed flotation of apatite from magnetite, silicate is used as a dispersing agent i.e. to hinder agglomeration. The collector is preferentially adsorbed by apatite, but a small fraction is also adsorbed by magnetite. Since silicate and collector will modify the magnetite surfaces differently, the former making the surface hydrophilic whereas the latter makes it hydrophobic, it is interesting to know whether one of the species already adsorbed can be substituted for the other one. This is interesting because it is known in practice that in the agglomeration of magnetite it is advantageous to have hydrophilic magnetite surfaces. In a process such as pelletizing, the rate of substitution is also very important. To obtain information about such competitive adsorption, the influence of already adsorbed oleate on silicate adsorption was studied in order to evaluate the possibility of substitution of oleate

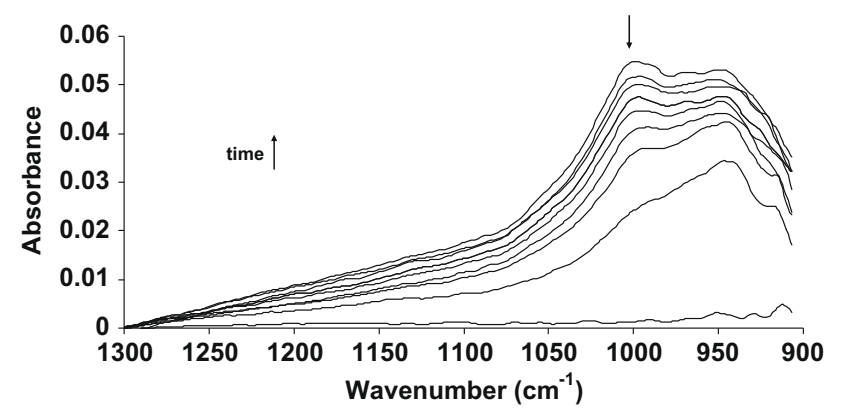

Fig. 7. ATR-FTIR spectra of silicate adsorbed onto magnetite from a $0.4 \mathrm{mM}$ aqueous silicate solution showing the spectral changes of adsorbed silicate with time $(4-100 \mathrm{~min})$. The arrow above the spectra denotes the frequency position where the maximum change occurred. for silicate anions. Subsequently, the substitution of already adsorbed silicate for oleate was investigated.

\subsubsection{Substitution of oleate for silicate}

Fig. 8 shows the effect of addition of water-glass to magnetite initially equilibrated with an aqueous solution of $0.1 \mathrm{mM}$ oleate. It is clear from Fig. 8a that the intensity of the methylene stretching vibrations only decreases a little upon increase of the silicate concentration, implying that silicate can not easily replace oleate at the magnetite surface. This result also supports the conclusion that oleate is chemisorbed at the magnetite surface, which was suggested in a previous section. Notice that the aqueous solution is all the time $0.1 \mathrm{mM}$ with respect to oleate in these experiments.

The peak intensity due to silicate adsorption also increased with increasing silicate concentration (Fig. 8b), which shows that an increased amount of silicate was adsorbed although magnetite had been made more hydrophobic by oleate. However, the band shape and peak positions are slightly different as compared with spectra recorded for the same time and concentration of silicate in the bulk, but adsorbed onto non-modified magnetite. This is reasonable since the environment of the adsorbed silicate species is different. For $1 \mathrm{mM}$ and $5 \mathrm{mM}$ silicate solutions, the peak position for the $\mathrm{Si}-\mathrm{O}$ stretch at $\sim 1020 \mathrm{~cm}^{-1}$ and $\sim 1040 \mathrm{~cm}^{-1}$ from adsorbed species at the non-modified magnetite surface, is detected at about $6 \mathrm{~cm}^{-1}$ to lower frequency at the modified surface, although a high frequency shift should be expected because of the hydrophobic environment. However, simultaneously the intensity of the shoulder at $\sim 1120 \mathrm{~cm}^{-1}$ is strongly diminished relative to the intensity of this shoulder for a non-modified surface. This difference in band shape and intensity of silicate absorption indicates less extensive or slower rate of polymerization of silicate when the surface of magnetite was treated with oleate. In addition, the results indicate that $\mathrm{Si}(\mathrm{OH})_{4}$ units $(\mathrm{pH}=8.5)$ have reached adsorption sites at the magnetite surface although it was first modified by equilibration with a $0.1 \mathrm{mM}$ oleate solution.
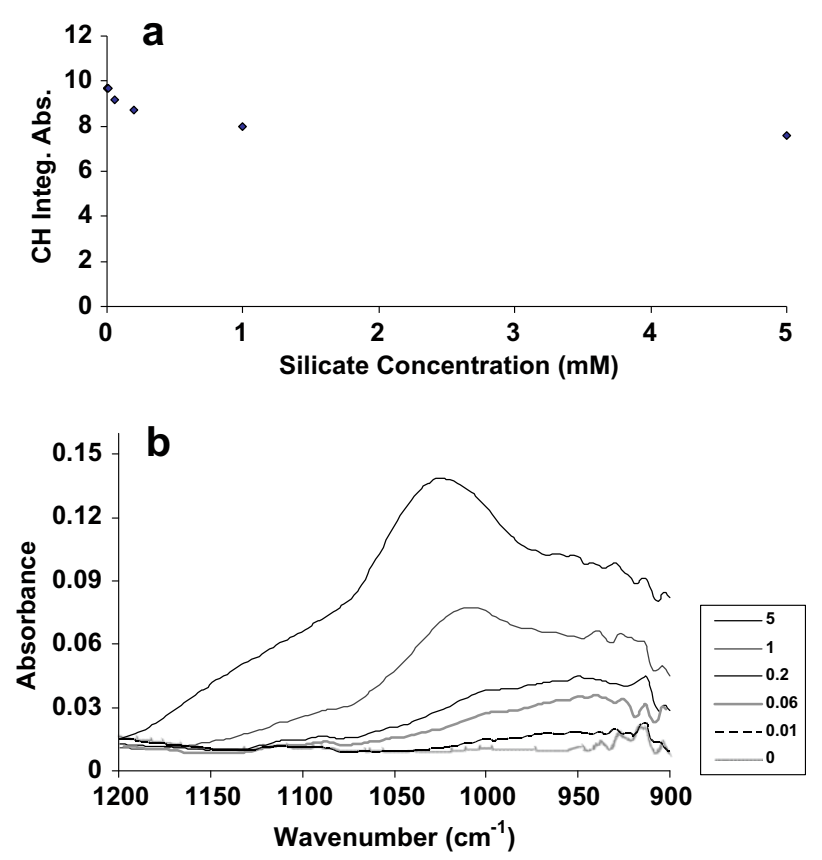

Fig. 8. Addition of water-glass to magnetite initially equilibrated with an aqueous solution of $0.1 \mathrm{mM}$ oleate (see text): (a) A plot of $\mathrm{CH}$ absorbance integrated between 2800 and $3000 \mathrm{~cm}^{-1}$ versus the bulk silicate concentration. (b) Infrared spectra of silicate at different concentrations, adsorbed on magnetite pre-treated with $0.1 \mathrm{mM}$ oleate solution. The insert to the right in (b) shows the bulk silicate concentration in $\mathrm{mM}$. Each spectrum was recorded after equilibration for $75 \mathrm{~min}$. 


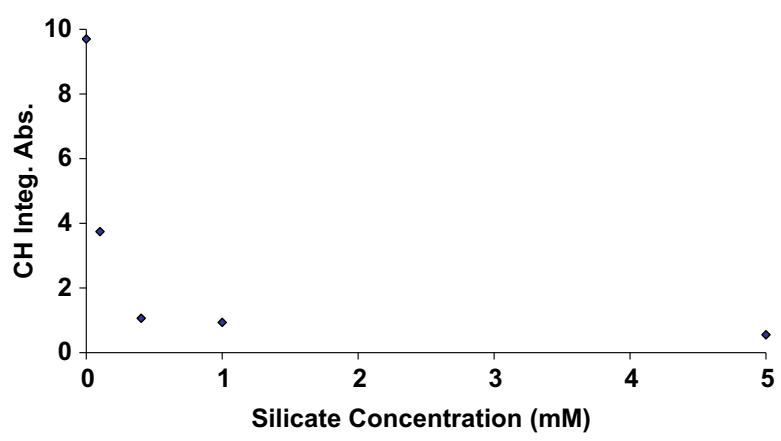

Fig. 9. Effect of water-glass on oleate adsorbed onto magnetite (see text). A plot of the integrated absorbance for the $\mathrm{CH}$ region between 2800 and $3000 \mathrm{~cm}^{-1}$ versus the bulk silicate concentrations used to modify the magnetite surface.

\subsubsection{Substitution of silicate for oleate}

Sodium silicate was first allowed to adsorb onto magnetite from various concentrations of aqueous silicate solutions for $100 \mathrm{~min}$. For each of the so prepared magnetite-silicate surfaces, the solution was made $0.1 \mathrm{mM}$ with respect to sodium oleate and this solution was continuously circulated through the flow cell monitoring the infrared spectra of oleate in situ. Fig. 9 shows the integrated absorbance of oleate in the $\mathrm{C}-\mathrm{H}$ stretching region versus the bulk silicate concentration used to modify the magnetite surface. Clearly, the amount of adsorbed oleate decreased with increasing amount of silicate on the magnetite surface, especially for magnetite prepared using silicate concentrations higher than $0.4 \mathrm{mM}$. As mentioned earlier, the $\mathrm{pH}$ of all solutions investigated was 8.5. The results show that oleate can adsorb on the silicate modified magnetite surface, but the extent of oleate adsorption is considerably lower above the bulk concentration where silicate species at the magnetite surface is supposed to form dimers or possibly polymers. The dimerization and polymerization of silicate at the magnetite surface seems to strengthen the attraction between silicate and iron oxide although increased surface coverage and thickness of the adsorbed silica layer may also be important.

It has been shown by others that $\mathrm{pH}$ and silica concentration are two important factors affecting the efficiency of water-glass as depressant in selective separation of apatite from iron oxide $[44,45]$. However, at lower sodium silicate concentrations than $0.4 \mathrm{mM}$, the adsorbed silicate species seemed to work mainly as a dispersing agent [46]. Already at this low concentration, the adsorbed silicate species tend to take part in condensation reactions at the magnetite surface (Fig. 7). Increasing the silicate concentration in the bulk from $0.1 \mathrm{mM}$ to $0.4 \mathrm{mM}$ strongly reduced the amount of adsorbed oleate (Fig. 9), whilst the intensity from $\mathrm{C}-\mathrm{H}$ stretching was only slightly reduced upon increasing the silicate concentration to $1 \mathrm{mM}$. Condensation of adsorbed silicate species seems therefore to be more efficient in order to avoid adsorption of oleate although adsorption was strongly prohibited already for magnetite treated with $0.1 \mathrm{mM}$ silicate solution.

\section{Conclusions}

Competition between sodium oleate and sodium silicate for a silicate/oleate modified magnetite surface was studied at $\mathrm{pH}=8.5$ using in situ ATR-FTIR spectroscopy. This technique allowed the detection of the adsorbate from low concentrations in Milli-Q water as solvent. Adsorption of oleate and silicate from aqueous solution was first studied separately. When oleate was adsorbed on magnetite, a broad infrared band was observed at $1535 \mathrm{~cm}^{-1}$ due to the asymmetric stretching of carboxylate, although the surface of magnetite is negatively charged at this $\mathrm{pH}(\mathrm{PZC} \sim 6.5)$. This indicated preferentially chemisorption of ole- ate onto the magnetite surface. The adsorption was shown to increase linearly with oleate concentration in the bulk up to $0.1 \mathrm{mM}$, with a contribution of physisorbed oleate at higher concentrations. The rate of oleate adsorption on magnetite showed a good correlation with pseudo-first-order kinetics at all concentrations studied with an apparent rate constant of $k_{1}=0.030 \pm 0.002 \mathrm{~min}^{-1}$.

The IR spectra of silicate adsorbed on magnetite showed a continuous shift to higher frequency with increasing concentration of silicate in the bulk. At a silicate concentration of $0.4 \mathrm{mM}$, a new band appeared above $\sim 1000 \mathrm{~cm}^{-1}$, a band that grew in intensity and shifted to higher frequency with time. The shift toward higher frequency was assigned to oligomerization of silicate at the magnetite surface, which might affect the depressive properties of silicate. It was shown that silicate in solution could not easily replace oleate already adsorbed at the surface although silicate was clearly adsorbed, but the polymerization/oligomerization of these silicate units were less extensive on magnetite initially treated with oleate as compared to an untreated magnetite surface. It was also shown that magnetite modified by silicate, even at low concentration, effectively reduced the adsorption of oleate from aqueous solution. Already at a silicate concentration of $0.4 \mathrm{mM}$, the amount of adsorbed sodium oleate was reduced to $10 \%$ of the amount adsorbed on a non-modified magnetite surface.

\section{Acknowledgment}

The Hjalmar Lundbom Research Centre (HLRC) is greatly acknowledged for the financial support.

\section{References}

[1] S.P.E. Forsmo, S.-E. Forsmo, B.M.T. Björkman, P.-O. Samskog, Powder Technol. 182 (2008) 444-452.

[2] A.R. Hind, S.K. Bhargava, A. McKinnon, Adv. Colloid Interface Sci. 93 (2001) 91114.

[3] P. Roonasi, A. Holmgren, J. Colloid Interface Sci. 333 (2009) 27-32.

[4] J. Ha, T.H. Yoon, Y. Wang, C.B. Musgrave, G.E. Brwon Jr., Langmuir 24 (2008) 6683-6692.

[5] K.A. McComb, D. Craw, A.J. McQuillan, Langmuir 23 (2007) 12125-12130.

[6] P. Borer, S.J. Hug, B. Sulzberger, S.M. Kraemer, R. Kretzschmar, J. Phys. Chem. C 111 (2007) 10560-10569.

[7] S.J. Parikh, J. Chorover, Langmuir 22 (2006) 8492-8500.

[8] C. Luengo, M. Brigante, J. Antelo, M. Avena, J. Colloid Interface Sci. 300 (2006) 511-518.

[9] A. Fredriksson, A. Holmgren, W. Forsling, Miner. Eng. 19 (2006) 784-789.

[10] L.T. Chiem, L. Huynh, J. Ralston, D.A. Beattie, J. Colloid Interface Sci. 297 (2006) 54-61.

[11] A. Fredriksson, M.L. Larsson, A. Holmgren, J. Colloid Interface Sci. 286 (2005) 16.

[12] A. Fredriksson, A. Holmgren, Miner. Eng. 21 (2008) 1000-1004.

[13] J. Drelich, A.A. Atia, M.R. Yalamanchili, J.D. Miller, J. Colloid Intreface Sci. 178 (1996) 720-732.

[14] M.L. Free, J.D. Miller, Langmuir 13 (1997) 4377-4382.

[15] J.D. Miller, J.J. Kellar, W.M. Cross, in: Advances in Coal and Mineral Processing Using Flotation, SME, Littelton, Colorado, 1989 (Chapter 4).

[16] W. Stumm, H. Huper, R.L. Champlin, Environ. Sci. Technol. 1 (1967) 221-227.

[17] R.K. Iler, The Chemistry of Silica, Wiley, New York, 1979.

[18] I.L. Svensson, S. Sjöberg, L.-O. Öhman, J. Chem. Soc., Faraday Trans. 82 (1986) 3635-3646.

[19] J.L. Bass, G.L. Turner, J. Phys. Chem. B 101 (1997) 10638-10644

[20] X. Yang, P. Roonasi, A. Holmgren, J. Colloid Interface Sci. 328 (2008) 41-47.

[21] P. Roonasi, A. Holmgren, Appl. Surf. Sci. 255 (2009) 5891-5895.

[22] L. Xiao, G. Xu, Z. Zhang, Y. Wang, G. Li, Colloid Surf. A 224 (2003) 199-206.

[23] N. Mahieu, D. Canet, J.M. Cases, J.C. Boubel, J. Phys. Chem. 95 (1991) 18441846.

[24] O. Ofor, J. Colloid Interface Sci. 174 (1995) 345-350.

[25] J. Shibata, D.W. Fuerstenau, Int. J. Miner. Process. 72 (2003) 25-32.

[26] W.Q. Gong, A. Parentich, L.H. Little, L.J. Warren, Langmuir 8 (1992) 118-124.

[27] J.D. Miller, J.S. Hu, R. Jin, Colloid Surf. A 42 (1989) 71-84.

[28] J.S. Hu, M. Misra, J.D. Miller, Int. J. Miner. Process. 18 (1986) 73-84.

[29] K.H. Rao, J.M. Cases, K.S.E. Forssberg, J. Colloid Interface Sci. 145 (1991) 330348.

[30] Yu-Tai Tao, J. Am. Chem. Soc. 115 (1993) 4350-4358.

[31] R.G. Snyder, H.L. Strauss, C.A. Elliger, J. Phys. Chem. 86 (1982) 5145-5150 
[32] J.J. Kellar, W.M. Cross, M.R. Yalamanchili, C.A. Young, J.D. Miller, Miner. Metall. Process. 43 (1993) 75-80.

[33] M.A. Osman, U.W. Suter, Chem. Mater. 14 (2002) 4408-4415.

[34] G.B. Deacon, R.J. Phillips, Coord. Chem. Rev. 33 (1980) 227-250.

[35] J. Degenhardt, A.J. McQuillan, Chem. Phys. Lett. 311 (1999) 179-184.

[36] J.D. Miller, W.H. Jang, J.J. Kellar, Langmuir 11 (1995) 3272.

[37] K. Nakamoto, Infrared and Raman spectra of inorganic and coordination compounds, Part B: Applications in Coordination Organometallic and Bioinorganic Chemistry, John Wiley \& Sons, New York, 1986. p. 232.

[38] R.M. Cornell, U. Schwertmann, The Iron Oxides, Structure, Properties, Reactions, Occurrences and Uses, second ed., Wiley-VCH, Weinheim, 2003. pp. 230, 235.
39] A. Fredriksson, A. Holmgren, Colloid Surf. A 302 (2007) 96-101.

[40] O. Ofor, A.C.I. Anusiem, J. Colloid Interface Sci. 220 (1999) 219-223.

[41] X. Yang, P. Roonasi, R. Jolsterå, A. Holmgren, Colloid Surf. A 343 (2009) 24-29.

[42] S. Sjöberg, J. Non-Cryst. Solids 196 (1996) 51-57.

[43] J. Lindgren, M. Karlsson, The WinSGW Program, Umeå University, Sweden, 2002.

[44] W.Q. Gong, C. Klauber, L.J. Warren, Int. J. Miner. Process. 39 (1993) 251-273

[45] W.Q. Gong, A. Parentich, L.H. Little, L.J. Warren, Int. J. Miner. Process. 34 (1992) 83-102.

[46] F.W. Su, K.H. Rao, K.S.E. Forssberg, P.-O. Samskog, Trans. Int. Miner. Metall. 107 (1998) C103-C110. 